\title{
In vitro wear behavior between enamel cusp and three aesthetic restorative materials: Zirconia, porcelain, and composite resin
}

\author{
Yong-Seok Jang1, Thuy-Duong Thi Nguyen², Young-Han $\mathrm{Ko}^{3,4}$, Dae-Woo Lee ${ }^{3}$, Byeong Ju Baik ${ }^{3}$, \\ Min-Ho Lee ${ }^{1}$, Tae-Sung Bae ${ }^{1 *}$ \\ ${ }^{1}$ Department of Dental Biomaterials, Institute of Oral Bioscience and Institute of Biodegradable Material, BK21 Plus Project, \\ School of Dentistry, Chonbuk National University, Jeonju, Republic of Korea \\ ${ }^{2}$ Odonto-stomatology Faculty, Hue University of Medicine and Pharmacy, Hue University, Hue City, Vietnam \\ ${ }^{3}$ Department of Pediatric Dentistry and Institute of Biodegradable Material, School of Dentistry, Chonbuk National University, \\ Jeonju, Republic of Korea \\ ${ }^{4}$ Plant Dental Clinic, Daejeon, Republic of Korea
}

\begin{abstract}
PURPOSE. The aim of this study was to identify the effects of three aesthetic restorative materials on the wear between tooth and restoration by a pin-on-disk manner. MATERIALS AND METHODS. Six aesthetic restorative materials were used to prepare disk specimens for wear test, which were Lava Zirconia as zirconia group, Vintage MP and Cerabien ZR as veneering porcelain group, Gradia Direct microhybrid composite containing prepolymerized fillers, Filtek Z250 microhybrid composite containing zirconia glass and colloidal silica particles, and Filtek Z350 nanocomposite as composite resin group. Vertical loss of the worn cusp, change of the surface roughness of the restoration materials, and the surface topography were investigated after wear test under 9.8-N contact load. RESULTS. The porcelain groups (Vintage MP and Cerabien ZR) caused the largest vertical loss of teeth when compared with those of the composite resin and zirconia groups, and Filtek Z250 microhybrid composite results in the second-largest vertical loss of teeth. The surface of Filtek Z350 nanocomposite was deeply worn out, but visible wear on the surface of the zirconia and Gradia Direct microhybrid composite was not observed. When the zirconia surface was roughened by sand-blasting, vertical loss of teeth considerably increased when compared with that in the case of fine polished zirconia. CONCLUSION. It was identified that microhybrid composite resin containing a prepolymerized filler and zirconia with reduced surface roughness by polishing were the most desirable restorative materials among the tested materials to prevent the two-body wear between aesthetic restorative material and tooth. [J Adv Prosthodont 2019;11:7-15]
\end{abstract}

KEYWORDS: Dental restoration; Dental abrasion; Restoration wear; Antagonist wear resistance

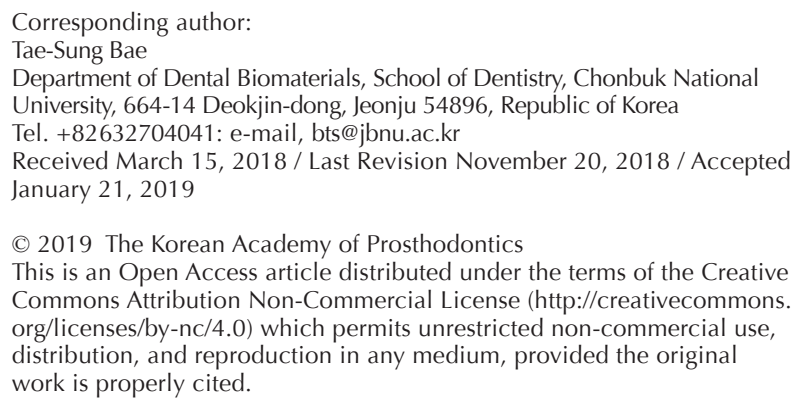

\section{INTRODUCTION}

Dental restoration is necessary to recover aesthetic aspects as well as functions of any missing tooth structures. Restorative materials performing for long periods of time can be worn in the oral cavity. The wear is defined as a complex phenomenon and an "overall effect" of a number of interrelated processes in which the surface of the material is gradually eroded and then removed. ${ }^{1,2}$ As reported by previous studies, the wear occurs by the following four major following mechanisms: adhesive wear, abrasive wear, corrosive wear, and fatigue wear. ${ }^{1,2}$ Additionally, other minor types of wear are responsible for approximately $5 \%$ of the total wear observed. $^{2}$ 
The degree of the wear varies based on external factors such as masticating force, types of ingested foods, pattern of food ingestion, and location of the tooth, as well as internal factors such as thickness and hardness of the enamel. ${ }^{3,4}$ Lambrechts et al. ${ }^{5}$ reported that the degree of vertical wear of the enamel that occurs in normal conditions was estimated at $29 \mu \mathrm{m} /$ year for molar and $15 \mu \mathrm{m} /$ year for premolar. This physiological wear in the oral cavity is accepted as a natural phenomenon. However, wear of the tooth may be accelerated by the materials used in restoring an antagonistic tooth. ${ }^{1,6}$

With respect to dental aesthetic restorations, veneering porcelain, ceramic, and composite resin are broadly used for anterior area as well as posterior area. Introduction of partially stabilized zirconia (PSZ) ceramic and development of new processing methods such as CAD/CAM have increased the use of zirconia ceramic with its excellent mechanical properties and high accuracy. ${ }^{7}$ In some studies, zirconia showed more wear resistance than other dental ceramics ${ }^{8}$ as well as other restorative materials. ${ }^{9,10}$

A layer of porcelain is veneered on a metal core or zirconia core to fully mimic the color and translucency of natural teeth. The porcelain layer comes in direct contact with antagonist teeth and is subjected to wear that further leads to veneer fracture. ${ }^{11}$ Previous studies indicated that the wear resistance of veneering porcelain is higher than that of zirconia but comparable to or lower than that of an enamel reference. ${ }^{10,12}$

In addition to porcelain and ceramic, composite resin is regarded as a popular aesthetic restoration material in dentistry. However, the defoliation of fillers as the wear progresses is a significant problem of composite resin when it is used in oral cavities. The filler particle size has been decreased to prevent this problem, and the filler composition has been modified. ${ }^{13-15}$ Dental micro-filled and hybrid composites with improved physical properties were introduced over a decade ago and are now commercially available and used in clinical treatment. ${ }^{14}$ Recently, the use of nanocomposites with nanofillers has been increased since the nanocomposites possess the aesthetic properties of microfilled composites as well as the physical properties and wear resistance of hybrid composites. ${ }^{16}$ Given these characteristics, nanocomposites are suitable for serving the anterior as well as posterior parts. ${ }^{13,14}$

Different structures and physical properties of dental restorative materials result in different wear. ${ }^{10}$ Specifically, the wear is highly dependent on hardness, fracture toughness, surface roughness, internal voids, and friction resistance of materials. ${ }^{10,17}$ Generally, ceramic materials have excellent aesthetic features in addition to good compressive strength and biocompatibility. However, it can cause more severe abrasiveness to opposing enamel when compared with that of composite resins. ${ }^{18}$ Thus, it is necessary to develop a suitable restorative material with excellent wear resistance to overcome this problem. Several studies examined the wear resistance of enamel with respect to the effect of composite resin, ${ }^{19-21}$ veneering porcelain, ${ }^{9,10,12}$ and zirco- nia ceramic. ${ }^{8-10}$ Nevertheless, few studies investigated the direct influence of these three restoration materials on enamel wear simultaneously. ${ }^{22}$

Therefore, the aim of the present study involved examining the effects of three aesthetic restorative materials on the two-body wear between tooth and restoration by a pinon-disk manner to recommend a suitable material for practical clinical use. Six groups of samples, composed of a type of zirconia ceramic, two types of veneering porcelain, and three types of composite resin, were used. In addition to well-polished zirconia, this study also investigated the wears of two roughened zirconia surfaces by sand-blasting at 2 atm and $4 \mathrm{~atm}$. The degree of wear for the aesthetic restorative material and enamel antagonist was observed and compared. The null hypothesis was that the zirconia ceramic with a higher degree of strength exhibits higher wear resistance when compared with porcelain and composite resin.

\section{MATERIALS AND METHODS}

This in vitro study involved evaluating the following six different dental restorative materials: a type of zirconia, two types of veneering porcelains, and three types of composite resins. The zirconia specimen corresponded to Lava Zirconia (LZ, 3M ESPE, St. Paul, MN, USA), which is a type of tetragonal zirconia polycrystalline block. Vintage MP (VM, Shofu Inc., Kyoto, Japan) and Cerabien ZR (CZ, Noritake, Nagoya, Japan) were selected for the porcelain groups. Vintage MP is a micro-ceramic system with a leucite-reinforced crystalline structure that is used in all metal frameworks. Additionally, Cerabien ZR corresponds to specially developed porcelain that is used to make all ceramic restorations using Alumina frameworks. The following three types of visible light-cured dental composite resins were used for the composite resin groups: Gradia Direct Posterior (GD, GC, Tokyo, Japan), Filtek Z250 (Z25, 3M ESPE, St. Paul, MN, USA), and Filtek Z350 (Z35, 3M ESPE, St. Paul, MN, USA). Specifically, Gradia Direct Posterior is a microhybrid composite with prepolymerized fillers, Filtek Z250 is a microhybrid composite zirconia glass, and Filtek Z350 is a nanocomposite.

A total of six groups were tested $(n=5$, Table 1). All the used materials were set at Vita shade A3. Prior to the wear testing, all the tested surfaces were ground to \#1200 $\mathrm{SiC}$ papers and polished with $1-\mu \mathrm{m}$ diamond paste (Buehler Ltd., Lake Bluff, IL, USA) to remove micro-defects. The final thicknesses of all samples were adjusted to $2 \pm 0.3$ $\mathrm{mm}$. The wear resistance was investigated through changes in the vertical dimension of the enamel cusp and in the surface topography of a test sample following a wear test on a pin-on-disk apparatus.

In order to prepare a zirconia sample, presintered CAD/ CAM blocks were sectioned into $25 \mathrm{~mm} \times 25 \mathrm{~mm} \times 2.5$ $\mathrm{mm}$ plates using a diamond cutting wheel under water-cooling. Both sides of each plate were polished using a \#1200 $\mathrm{SiC}$ paper to make the surface smooth as well as to obtain a 
Table 1. Materials used in this study

\begin{tabular}{llclll}
\hline Classification & Product & $\begin{array}{c}\text { Group } \\
\text { code }\end{array}$ & Characteristic & Manufacturer \\
\hline Zirconia & Lava & LZ & Partially stabilized zirconia ceramic for CAD/CAM & 3M ESPE, St. Paul, MN, USA \\
\multirow{2}{*}{ Veneering porcelain } & Cerabian ZR & CZ & Feldspathic porcelain, veneering on zirconia frameworks & Noritake, Nagoya, Japan \\
& Vintage MP & VM & Feldspathic porcelain, veneering on metal frameworks & Shofu, Kyoto, Japan \\
& Gradia Direct & GD & Microhybrid composite containing silica and prepolymerized filler & GC, Tokyo, Japan \\
Composite resin & Filtek Z250 & Z25 & $\begin{array}{l}\text { Microhybrid composite containing zirconia glass and colloidal } \\
\text { silica particles }\end{array}$ & 3M ESPE, St. Paul, MN, USA \\
& Filtek Z350 & Z35 & Nanocomposite containing zirconia/silica and silica nanoparticles & 3M ESPE, St. Paul, MN, USA \\
\hline
\end{tabular}

Table 2. Firing schedules of veneering ceramic materials

\begin{tabular}{lcccccccc}
\hline \multirow{2}{*}{ Materials } & \multirow{2}{*}{ Code } & \multicolumn{2}{c}{ Pre-Drying } & TRI $\left({ }^{\circ} \mathrm{C} / \mathrm{min}\right)$ & $\mathrm{FT}\left({ }^{\circ} \mathrm{C}\right)$ & $\mathrm{V} 1\left({ }^{\circ} \mathrm{C}\right)$ & $\mathrm{V} 2\left({ }^{\circ} \mathrm{C}\right)$ & $\mathrm{HT}(\mathrm{min})$ \\
\hline Cerabian ZR & $\mathrm{ST}\left({ }^{\circ} \mathrm{C}\right)$ & $\mathrm{DT}(\mathrm{min})$ & & & & \\
Vintage MP & $\mathrm{CZ}$ & 450 & 8 & 45 & 930 & 450 & 930 \\
\hline
\end{tabular}

ST: starting temperature; DT: drying time; FT: final temperature; TRI: temperature rate increase; V1: vacuum on; V2: vacuum off; HT: holding time.

thickness of $2 \mathrm{~mm}$. Subsequently, all specimens were fired at $1450^{\circ} \mathrm{C}$ for 2 hours with a temperature increase speed of $8.3^{\circ} \mathrm{C} / \mathrm{min}$ and were then cooled inside a furnace to room temperature.

In order to check the effects of surface roughness on the wear resistance of ceramic plates, two groups of ceramic plates ( $\mathrm{n}=5 /$ group) were air-abraded with $50 \mu \mathrm{m}$ alumina particles for $10 \mathrm{~s}$ at either $2 \mathrm{~atm}$ pressure or $4 \mathrm{~atm}$ pressure, an angle of $90^{\circ}$, and a distance of $10 \mathrm{~mm}$ from the surface. The air-abraded specimens were then cleaned in an ultrasonic bath with distilled water and dried at $50^{\circ} \mathrm{C}$ for 12 hours.

Porcelain discs were obtained by preparing porcelain slurry, build-up in a metal mold (with an internal diameter of $28 \mathrm{~mm}$ and a thickness of $2 \mathrm{~mm}$ ), and firing according to the manufacturer's instructions (Table 2).

Each resin composite material was inserted in a split Teflon mold (with an internal diameter of $20 \mathrm{~mm}$ and a thickness of $2 \mathrm{~mm}$ ). Mylar strips were placed on the top and bottom of the mold surface. Flat surface was obtained by compressing the mold between two glass slabs after removing excess material. Then the superior and inferior sides of the resin composite were cured for $20 \mathrm{~s}$ respectively using three light curing units (Optilux, Demetron, Danbury, CT, USA) with an output light intensity corresponding to $600 \mathrm{~mW} / \mathrm{cm}^{2}$.

In order to obtain opposing enamel cusps (antagonists), 40 similar-sized human 2 nd premolars without obvious wear scar, crack and fracture, which were extracted from adolescents between the ages of 13 and 17 for orthodontic treatment, were selected and preserved in distilled water at $4^{\circ} \mathrm{C}$. The buccal cusps were cleaned and polished with pumice flour and selected as the antagonists. The teeth were per-

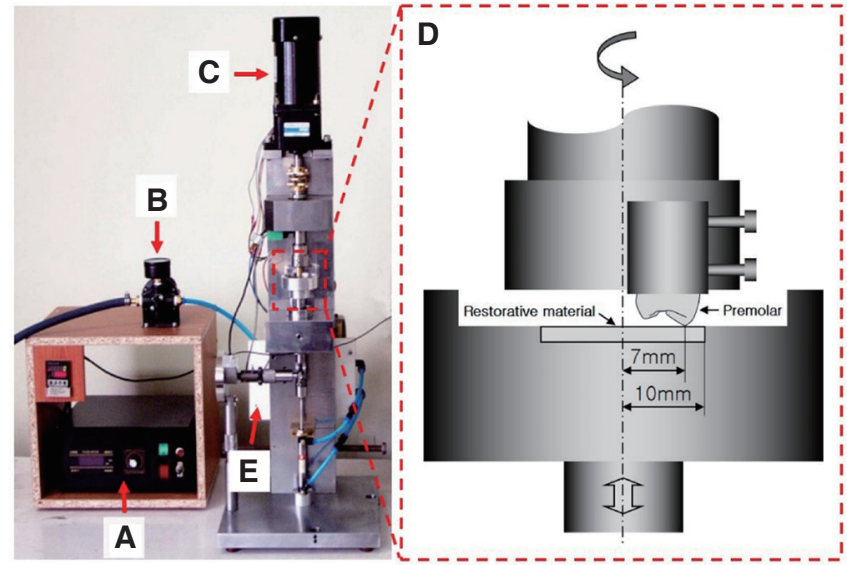

Fig. 1. Electromechanical wear tester. (A) Power and motor controller, (B) Pressure regulator, (C) Speed control motor, (D) Test chamber, (E) Air controller.

pendicularly embedded in auto-polymerizing acrylic resin using a cylinder-shaped steel mold (with a height of $20 \mathrm{~mm}$ and a diameter of $10 \mathrm{~mm}$ ), which ensured that the buccal cusps were higher than the palatal cusps.

Wear test was conducted using electromechanical wear tester (Model: KD-WT02, Invertech, Co., Jeongeup, Korea) in a pin-on-disc contact configuration between the sample and enamel cusp under a wet condition at room temperature. The testing material was attached on a stationary disc that was placed in a chamber of distilled water. The premolar cylinder was fixed into a stylus that was set to create a rotational sliding enamel cusp (pin) relative to the testing sample (disc) (Fig. 1). 
The tests were performed with a normal loading of 9.8 $\mathrm{N}$ and a rotational velocity corresponding to $100 \mathrm{rpm}$. The changes in the dental cusps and antagonist samples were investigated with sliding distances corresponding to $100 \mathrm{~m}$, $200 \mathrm{~m}, 300 \mathrm{~m}, 400 \mathrm{~m}$, and $500 \mathrm{~m}$. The vertical loss of the dental cusp was measured using a micrometer with an accuracy of $0.1 \mu \mathrm{m} / 100 \mathrm{~m}$ (ID-C125B, Mitutoyo Co., Kawasaki, Japan).

With respect to the testing materials, the surface roughness ( $\mathrm{Ra}$ ) was randomly measured at five different locations using a surface roughness tester (Surftest SV-3000M4, Mitutoyo Instruments, Kawasaki, Japan) with the stylus moving in a direction along a length of $0.25 \mathrm{~mm}$ at a speed of $0.2 \mathrm{~mm} / \mathrm{s}$. Sequentially, the surface topography of the specimens was examined using a field emission scanning electron microscope (FE-SEM, S800, Hitachi, Tokyo, Japan) at Korea Basic Science Institute (KBSI, Jeonju, Korea).

Data were statistically analyzed using statistical software SPSS ver12.0 (SPSS Inc., Chicago, IL, USA). One-way analysis of variance (ANOVA) with Tukey test was performed to compare the wear resistance among the groups. The $P$ level was set at 0.05 .

\section{RESULTS}

Fig. 2 illustrates a decrease in the vertical dimension of enamel cusp based on the distance during a $500 \mathrm{~m}$ sliding contact between the restorative material and the enamel cusp under a load of $9.8 \mathrm{~N}$. The veneering porcelain groups (VM and CZ) caused the largest amount of vertical loss of the enamel cusp during the wear test. From $100 \mathrm{~m}$ to $500 \mathrm{~m}$, LZ, GD, and Z35 groups did not cause any further wear of the enamel cusp, but the vertical loss of the enamel cusp Z25 group increased slightly as the sliding distance increased.

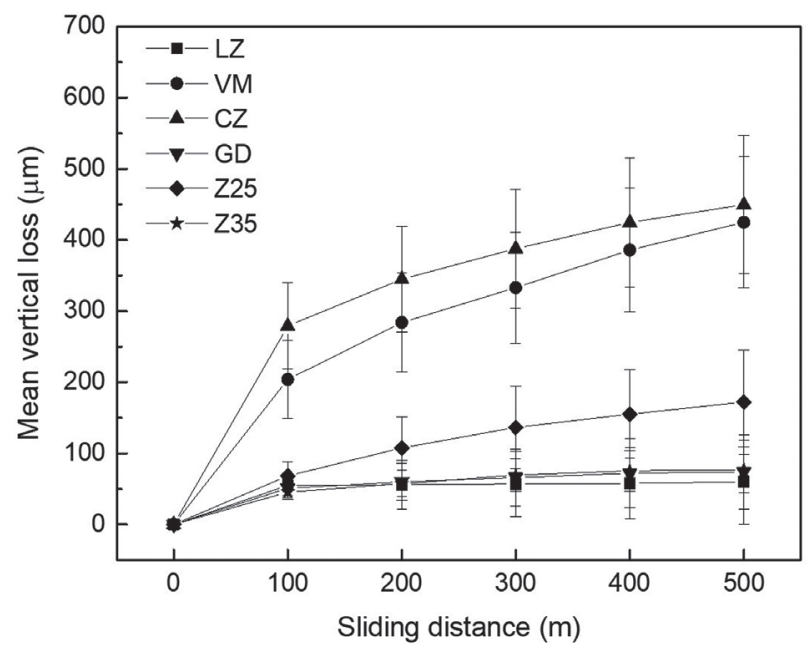

Fig. 2. Vertical loss of premolar cusp opposing the different materials of 6 groups with sliding distance during wear testing.
Fig. 3 shows the final record of vertical loss after the wear testing. As confirmed by the figure, the greatest wear of the antagonist cusps was observed in the porcelain groups $(P<.05)$ after the $500 \mathrm{~m}$ sliding contact. LZ and composite Z35 groups exhibited lower values when compared with that of the Z25 group $(P<.05)$.

Fig. 4 shows the changes in the surface roughness of the restorative materials with sliding distance. The surface roughness of Z35 and VM groups sharply increased at the initiatory stage of the wear test, and the highest $\mathrm{Ra}$ value was measured in Z35 group after the wear test. VM group showed higher Ra value when compared with the other groups except Z35 group after the wear test.

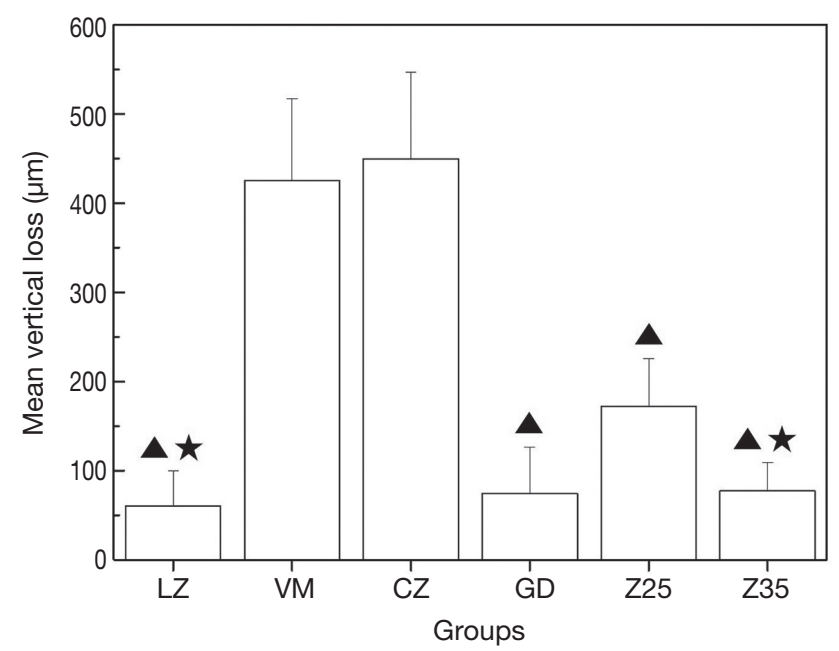

Fig. 3. Mean vertical loss of antagonist cusp opposing different materials after wear testing.

$\boldsymbol{\Delta}$ indicates the significant differences with veneering porcelain groups (VM, CZ) $(P<.05)$.

$\star$ indicates the significant differences with composite resin $\mathrm{Z} 25$ group $(P<.05)$.

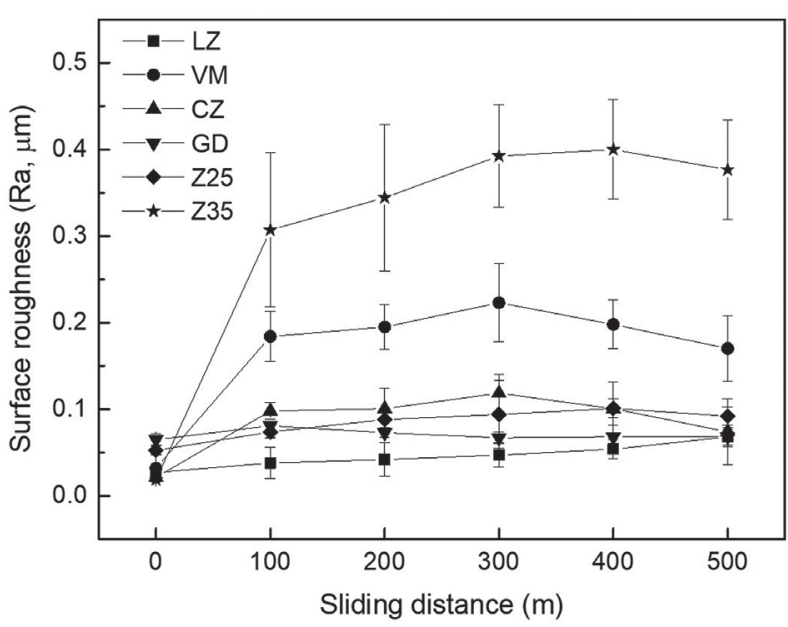

Fig. 4. Surface roughness $(\mathrm{Ra})$ of restorative materials opposing premolar cusp with sliding distance during wear testing. 
Fig. 5 and Fig. 6 show representative FE-SEM images for the wear surface of restorative materials after the wear test. The six groups showed different wear patterns. The zirconia surface with a smooth surface has not changed after the wear test (Fig. 5A, 5B). The surfaces of the two porcelain groups became rough with partial delamination (Fig. 5C - 5F). In the three composite resin groups, the wear track on each material exhibited different topographies (Fig. 6). The indistinct scratches were observed on the surface of GD group along the sliding track, which had a relatively smooth and uniform surface (Fig. 6A, 6B). A few small microcracks and fractured regions were just confirmed at high magnification (Fig. 6C). A shallow and broad wear track was observed on the Z25 group (Fig. 6D). Also, the worn surface was rather smooth but fatigue cracks were apparently observed entirely on the surface (Fig. 6E), and the micro-cracks was observed at interfaces between filler particles and the resin matrix (Fig. 6F). Deeply worn wear track was clearly observed on the surface of Z35 group (Fig. 6G), and a coarse understructure with several pits and resin smearing was exposed (Fig. 6H, 6I).

In order to investigate the effect of the surface roughness of zirconia on the wear resistance, two zirconia samples sandblasted at different pressures (2 atm and $4 \mathrm{~atm})$ were used in the wear test and compared with that of the polished one.
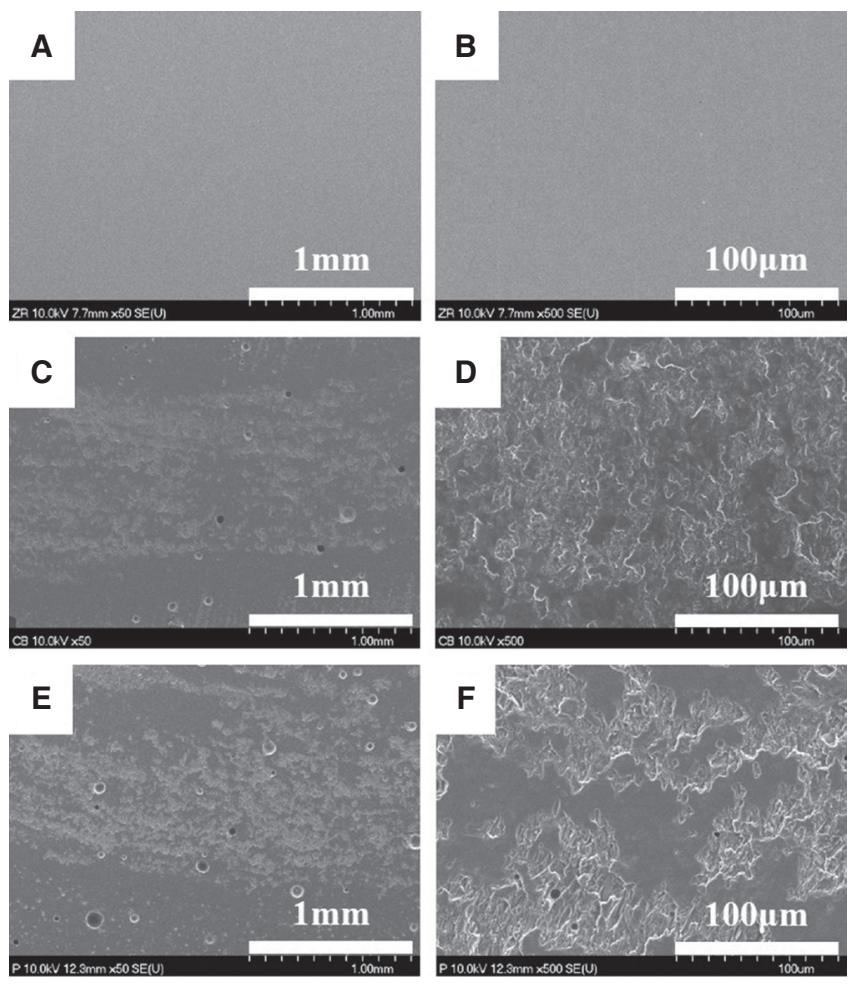

Fig. 5. FE-SEM images of worn surfaces of restorative materials after sliding contact with premolar cusp. (A) LZ $(\times 50)$, (B) LZ $(\times 500),(C) \mathrm{CZ}(\times 50),(\mathrm{D}) \mathrm{CZ}(\times 500),(\mathrm{E})$ $\mathrm{VM}(\times 50),(\mathrm{F}) \mathrm{VM}(\times 500)$.
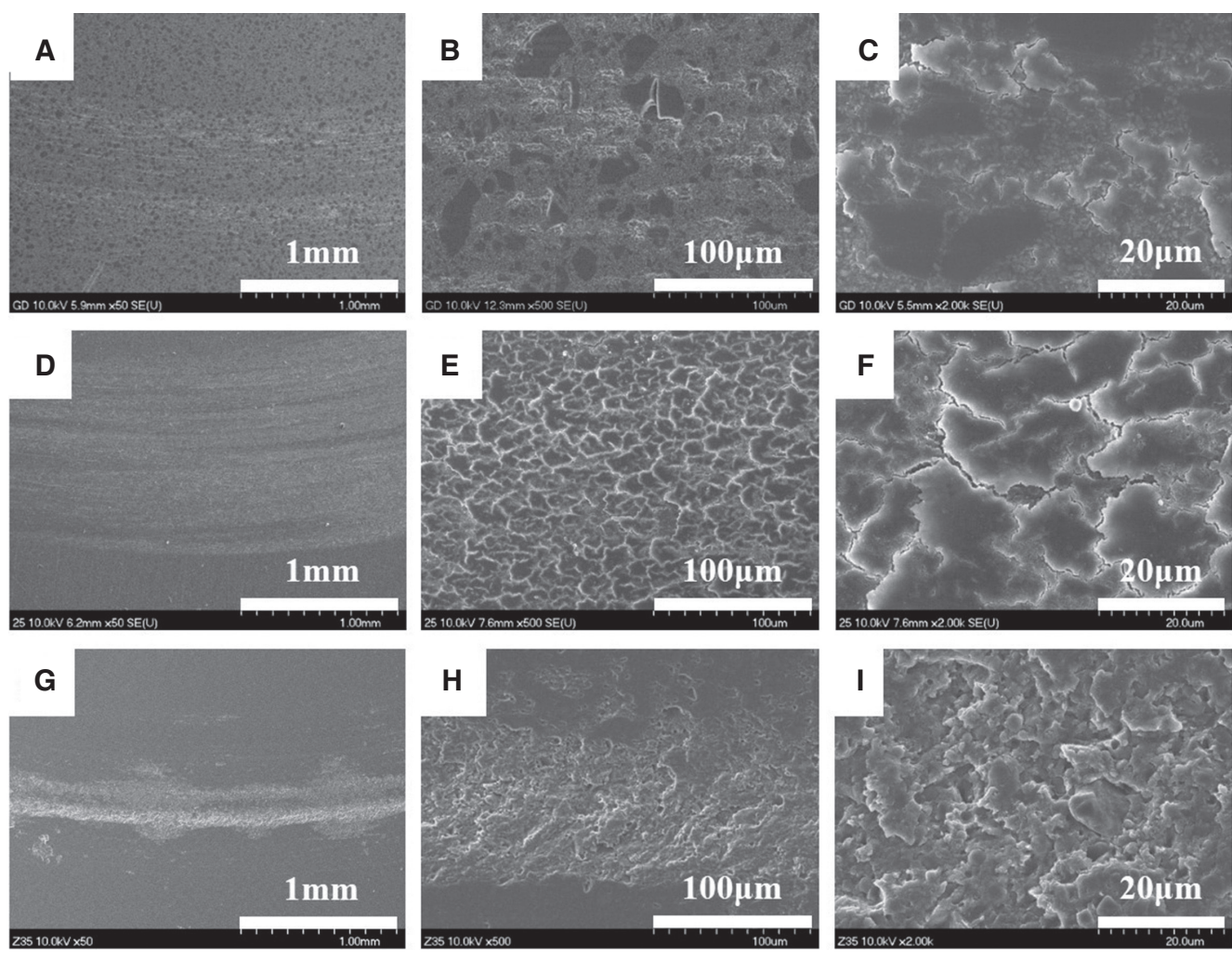

Fig. 6. FE-SEM images of worn surfaces of composite materials after sliding contact with premolar cusp. (A) GD (× 50), (B) GD (× 500), (C) GD (× 2000), (D) Z25 ( $\times 50)$, (E) Z25 ( $\times 500),(F) Z 25$ (× 2000), (G) Z35 (× 50), (H) Z35(× 500), (I) Z35 (× 2000). 
Fig. 7 illustrates a decrease in the vertical dimension of the enamel cusp during a sliding contact on the zirconia samples. There was a considerable increase in the vertical loss of the enamel cusp with increased surface roughness of the zirconia by sand-blasting.

Fig. 8 shows the changes in the surface roughness of polished and sand-blasted zirconia samples during wear test. The initial surface roughness increased with increase in the level of spraying pressure. The polished zirconia maintained its surface roughness during the wear test. The roughened zirconia at $2 \mathrm{~atm}$ exhibited a slight decrease in roughness following $100 \mathrm{~m}$ of sliding. Additionally, the roughness of the zirconia at $4 \mathrm{~atm}$ decreased noticeably and reached the same level as that of the $2 \mathrm{~atm}$ group at $200 \mathrm{~m}$, which was retained subsequently. However, the surface roughness of

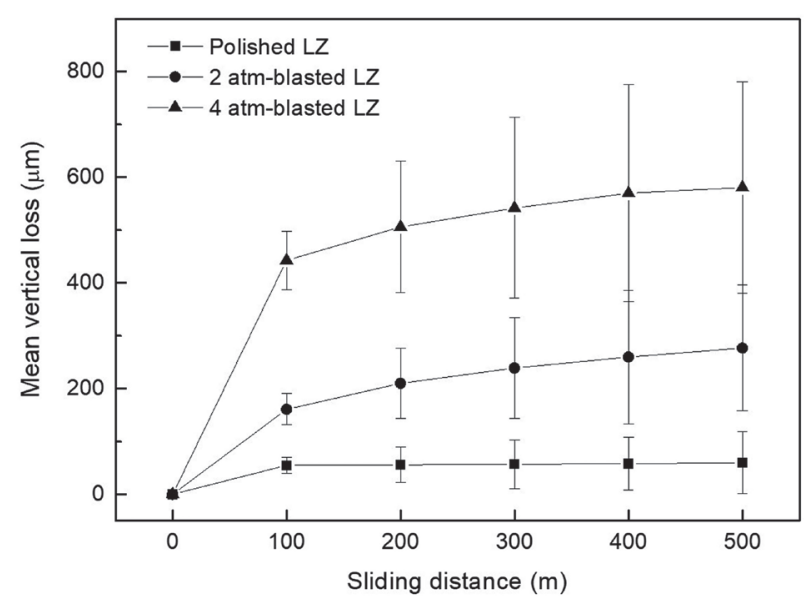

Fig. 7. Vertical loss of premolar cusp opposing the polished, $2 \mathrm{~atm}$-blasted and $4 \mathrm{~atm}$-blasted LZ groups with sliding distance during wear testing.

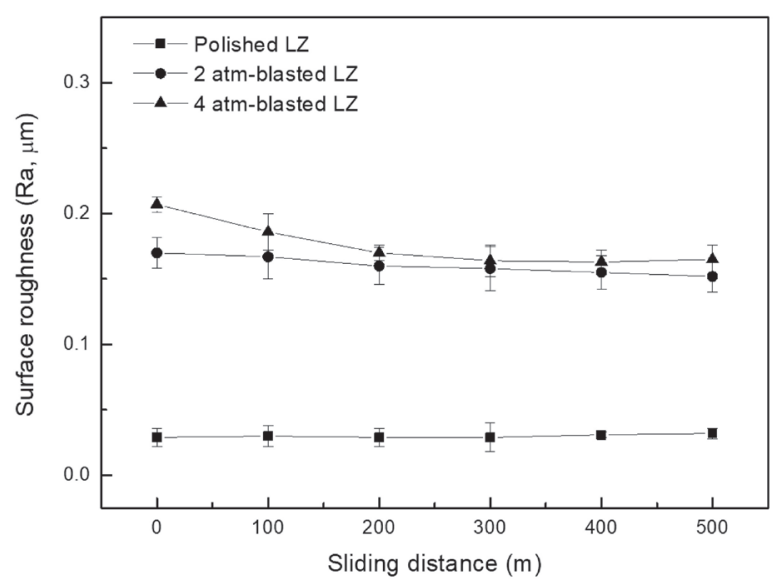

Fig. 8. Surface roughness (Ra) of the polished, 2 atmblasted and 4 atm-blasted LZ groups opposing premolar cusp with sliding distance during wear testing. sandblasted zirconia has much higher Ra value than that of polished zirconia after wear test. The FE-SEM micrographs of the wear track exhibited rough worn surfaces on the sandblasted samples as shown in Fig. 9.

\section{DISCUSSION}

In the oral cavity, dental restorative materials play an important part in wear and show different wear patterns..$^{23}$ Materials can be worn by enamel or cause the aggressive wear of enamel. Thus, it is important to evaluate the wear behavior between the restorative materials and the opposing enamel. Since it is difficult to observe the wear directly, the wear can be detected based on indirect factors such as vertical loss, volume loss, and topography on the worn surface. ${ }^{4,15,23,24}$

The wear test can be classified into a 2-body wear test and a 3-body wear test. ${ }^{1}$ The 2-body wear test attempts to simulate attrition created by direct occlusal contact of teeth or restorative materials during grinding and bruxism. The 3-body wear test attempts to simulate the masticatory phase when a food bolus exists. The intraoral wear process occurs between the opposing enamel and restorative materials in patterns such as 2-body wear, 3-body wear, or a combination of both types. ${ }^{25,26}$ With respect to the possibility of the wear of dental restoration materials, previous studies were performed with various testing materials and different in vitro wear apparatus. ${ }^{4,8,19}$ However, an in vitro method in which the oral environment cannot be accurately simulated, and the lack of precise measuring techniques makes it difficult to correlate the results of different studies. ${ }^{1,2}$ Thus, the degree of the wear varies with the experimental conditions although the same materials are used.

In the present study, the time-dependent wear behavior of various restoration materials was investigated via a 2-body wear test with a pin-on-disk setting in a liquid environment, which was considered as a suitable model for studying the fundamental relationships between the microstructure and wear mechanisms. ${ }^{24}$ The premolar cusp was used as the enamel antagonist and three groups of restorative materials (zirconia, veneering porcelain, and composite resin) were tested. The reduction in the vertical dimension of the antagonistic tooth examined whether damages existed between the antagonistic tooth and restoration materials
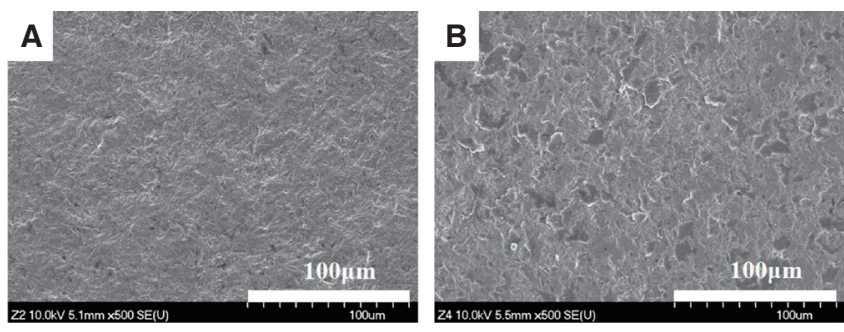

Fig. 9. FE-SEM images of worn surfaces for (A) 2 atmblasted zirconia and (B) 4 atm-blasted zirconia after sliding contact with premolar cusp. 
due to the wear, and FE-SEM examination was performed to investigate the changes in surface topography. The corresponding hypothesis was that the zirconia ceramic group would have high wear resistance when compared with those of porcelain or composite resin groups. The variance for the reduction in the vertical dimension of the antagonistic tooth was relatively high after the wear test in this study. This could be because the natural tooth was used as the antagonist without any standardization and wear behavior differed across layers in the tooth structure, resulting in a slight inconsistency with respect to the obtained results. ${ }^{17,27}$ Despite the aforementioned issues, natural enamel antagonists are preferred for the simulation of wear in the occlusal contact area. ${ }^{1,9}$

The results revealed that the zirconia ceramic caused the lowest degree of vertical loss for the antagonist teeth. Additionally, the zirconia surface did not change after the wear test. The high strength, hardness, and fracture toughness of the zirconia enabled it to maintain a smooth surface during the wear test and to resist wear, and this was in accordance with the results of previous studies. ${ }^{89}$ In contrast, the veneering porcelain groups caused severe wear on the opposing enamel and a partial loss on the veneering porcelain. Ekfeldt and Olio ${ }^{28}$ reported that when the enamel was in occlusion with feldspathic porcelain, gold and resin, the wear of the enamel was the biggest in the case of feldspathic porcelain. Additionally, Mahalick et al..$^{29}$ showed that the degree of wear between enamel and porcelain was 2.4 times higher than that between enamel and resin, and was 17 times higher than that between enamel and metal alloy. Enamel had a lower hardness when compared with that of feldspathic porcelain, and this could cause wear of enamel. ${ }^{9}$ Furthermore, veneering porcelain has the following two different main components: glass matrix and leucite crystals with differences in the relative degree of wear. Thus, it was inferred that abrasive wear could occur during a wear test and accelerate the surface roughness and the wear of the antagonistic tooth. ${ }^{12}$ Thus, it is recommended that the use of porcelain should be avoided on the occlusal surface of the posterior teeth.

With respect to composite materials, the filler particles play an important role for both hardness and wear resistance. ${ }^{15}$ Thus, each type of tested composites in this study showed different wear behaviors. The microhybrid GD group with organic composite filler caused a slight change in the surface roughness of material and the vertical dimension of antagonistic tooth after wear test. This could be due to sliding of the antagonistic tooth on the micro composite fillers where organic particles were added at a high density. Additionally, the universal Filtek Z250 microhybrid composite showed comparable wear resistances of materials but caused a strong decrease in the vertical dimension of the antagonistic tooth. A study by Blackham et al. ${ }^{30}$ also indicated that Filtek Z250 composite showed greater microhardness due to a wide range of filler particles when compared with that of Gradia Direct Posterior microhybrid composite. Thus, the addition of zirconia glass particles in the filler component resulted in the different characteristics of ceramics with those of resin, and thereby led to an abrasive wear for the antagonistic teeth. Furthermore, the vertical loss of the antagonist teeth for Z25 microhybrid composite group was twice that of the nanocomposite Z35. This finding is in agreement with the results obtained in a study by Gondon and Ferracane, in which the antagonistic enamel wear for the composites containing larger filler particle sizes exceeded that of the composites containing smaller filler particle sizes. ${ }^{24}$ However, with respect to the wear of restorative materials, the nanocomposite showed the highest increase in surface roughness. The nanocomposite was developed to increase the wear resistance. ${ }^{16}$ However, Yesil et al. ${ }^{31}$ reported that the incorporation of nanofillers into dental composite resin materials may not improve clinical wear properties when compared to the addition of microhybrid and microfilled materials. A clinical study indicated that the mean vertical and volume wear of the nanofilled group was not significantly different from those of the microhybrid group at the four and five-year recall. ${ }^{32}$ In this study, the nanocomposite Z35 group exhibited a small vertical loss on the opposite teeth but high wear on its own surface. A study by Ghazal and $\operatorname{Kern}^{33}$ also reported that human enamel displayed less wear when compared with that of nanofilled composite resin. This could be due to the low fragile resistance of the nanocomposite, which leads to the removal of material without resistance under an external force from the antagonist.

Overall, among the tested materials, the zirconia LZ and the organic filler-containing microhybrid composite resin GD exhibited good wear resistance and caused less wear on the opposite enamel.

For the mechanism of the wear between the tooth and the restorative materials, abrasive wear, fatigue wear, and corrosive wear are the main types of wear mechanisms, which typically occur in the oral cavity. ${ }^{2}$ In this study, the contact between the veneering porcelain and the enamel cusp was evidently affected by abrasive wear with partial delamination. In case of the composite resin, it was not easy to predict the wear mechanism due to its composition that involved hard phases within a softer matrix. ${ }^{34,35}$ In the study, the three types of composite materials exhibited different wear patterns, which were attributed to different wear mechanisms. The microhybrid GD containing prepolymerized fillers was slightly affected by abrasive wear. Z25 microhybrid composite exhibited several fatigue cracks on the worn surface, and the nanocomposite Z35 showed abrasive wear. Braem et al. ${ }^{36}$ reported that abrasive wear and fatigue wear were the major mechanisms that were observed in the composite resin restoration. Mair et al..$^{35}$ discussed that a hybrid composite resin with a mixture of different size fillers resisted abrasive wear, thereby leading to the occurrence of fatigue fractures. This process was described as the transfer movement of the surface molecules to the subsurface, causing the rupture of intermolecular bonds and a zone of "subsurface damage." Eventually, microcracks formed within the subsurface, followed by a frag- 
mental loss of material that induces fatigue wear if the microcracks propagate to the surface. ${ }^{1}$

In order to investigate the effect of surface roughness on wear, the zirconia surface was roughened by sandblasting at $2 \mathrm{~atm}$ and $4 \mathrm{~atm}$. As observed from the wear test, the vertical loss of the enamel antagonist was affected by the surface roughness of zirconia. The micro-grinded zirconia had a smooth surface, which led to the sliding of the antagonistic ceramic on the smooth surface. This was accompanied by abrasive wear that occurred on the enamel cusp opposing the rough zirconia surface. Irrespective of the initial condition of surface, the roughness of the polished and sand-blasted samples exhibited unnoticeable changes during the wear test. This finding was supported by the results of a study by Ghazal and Kern ${ }^{33}$ in which the surface roughness of the antagonistic ceramic significantly influenced the wear of human enamel. Preis et al. ${ }^{37}$ also reported that the wear process marginally affected the roughness change of both polished and grinded zirconia. Thus, it is necessary for the zirconia to be well-polished to maintain a high wear resistance for use in clinics. ${ }^{33,37}$ It is recommended that the average surface roughness of ceramic following polishing should not exceed $0.75 \mu \mathrm{m}{ }^{33}$

The wear of the tooth and restoration materials could lead to a reduction in the occlusal dimension, malocclusion, and poor aesthetic outcomes. ${ }^{6,12}$ Evidently, wear is an essential factor that should be considered in the selection of materials during a restoration procedure. Ideal crown restoration materials should exhibit profiles of wear resistance similar to that of the enamel with respect to physiological conditions. ${ }^{38}$ Thus, the results of this study indicated that it is necessary to use well-polished zirconia or GD microhybrid composite resin containing prepolymerized filler, since they are effective to prevent the wear of the antagonistic tooth and the restoration. However, as in the case of other in vitro studies, these investigations did not specify clinically observed wear. Further research is required to verify the results of this study reliably.

\section{CONCLUSION}

In this study, a 2-body wear test was performed in a pin-ondisk manner wherein the enamel cusp of the premolar had displayed an occlusal relationship with a type of zirconia ceramic, two types of porcelain, and three types of composite resin. The following conclusions can be drawn:

The greatest antagonist enamel antagonist wear was observed when veneering porcelains were used, and Filtek Z250 microhybrid composite containing zirconia glass and colloidal silica particles caused secondly higher the second greatest vertical loss of teeth.

Secondly, the deepest worn track was obviously formed on the surface of Filtek Z350 nanocomposite, but there was no visible wear on the surface of the zirconia and Gradia Direct microhybrid composite surface containing prepolymerized fillers after wear test.

More vertical loss of premolar cusp was shown by increasing the surface roughness of the zirconia.

Considering these results, it is recommended to fabricate the aesthetic restoration using a microhybrid composite resin containing a prepolymerized filler or to reduce the surface roughness of the zirconia surface through micro-grinding in order to prevent the reduction in occlusal vertical dimension and damages of both aesthetic restoration and tooth by minimizing the antagonistic wear.

\section{ORCID}

Yong-Seok Jang https://orcid.org/0000-0002-2757-232X

Thuy-Duong Thi Nguyen bttps://orcid.org/0000-0003-0552-1916

Young-Han Ko bttps://orcid.org/0000-0003-4555-6566

Dae-Woo Lee https://orcid.org/0000-0002-9942-2400

Byeong-Ju Baik https://orcid.org/0000-0002-5400-4715

Min-Ho Lee https://orcid.org/0000-0001-6142-4876

Tae-Sung Bae https://orcid.org/0000-0002-8307-4544

\section{REFERENCES}

1. Lambrechts P, Debels E, Van Landuyt K, Peumans M, Van Meerbeek B. How to simulate wear? Overview of existing methods. Dent Mater 2006;22:693-701.

2. Mukatash Nimri EG. Wear mechanisms and wear investigations of dental materials; a review of the literature. Arch Oral Dent Res 2015;2:3.

3. Smith BG, Bartlett DW, Robb ND. The prevalence, etiology and management of tooth wear in the United Kingdom. J Prosthet Dent 1997;78:367-72.

4. Elmaria A, Goldstein G, Vijayaraghavan T, Legeros RZ, Hittelman EL. An evaluation of wear when enamel is opposed by various ceramic materials and gold. J Prosthet Dent 2006;96:345-53.

5. Lambrechts P, Braem M, Vuylsteke-Wauters M, Vanherle G. Quantitative in vivo wear of human enamel. J Dent Res 1989; 68:1752-4.

6. Lee A, He LH, Lyons K, Swain MV. Tooth wear and wear investigations in dentistry. J Oral Rehabil 2012;39:217-25.

7. Guazzato M, Albakry M, Ringer SP, Swain MV. Strength, fracture toughness and microstructure of a selection of allceramic materials. Part II. Zirconia-based dental ceramics. Dent Mater 2004;20:449-56.

8. Albashaireh ZS, Ghazal M, Kern M. Two-body wear of different ceramic materials opposed to zirconia ceramic. J Prosthet Dent 2010;104:105-13.

9. Kim MJ, Oh SH, Kim JH, Ju SW, Seo DG, Jun SH, Ahn JS, Ryu JJ. Wear evaluation of the human enamel opposing different Y-TZP dental ceramics and other porcelains. J Dent 2012;40:979-88.

10. Preis V, Hahnel S, Kolbeck C, Behrend D, Warkentin M, Handel G, Rosentritt M. Wear performance of dental materials: A comparison of substructure ceramics, veneering ceramics, and non-precious alloys. Adv Eng Mater 2011;13:B432-B9.

11. Kimmich M, Stappert CF. Intraoral treatment of veneering porcelain chipping of fixed dental restorations: a review and clinical application. J Am Dent Assoc 2013;144:31-44. 
12. Preis V, Behr M, Kolbeck C, Hahnel S, Handel G, Rosentritt M. Wear performance of substructure ceramics and veneering porcelains. Dent Mater 2011;27:796-804.

13. Jandt KD, Sigusch BW. Future perspectives of resin-based dental materials. Dent Mater 2009;25:1001-6.

14. Christensen GJ. Remaining challenges with Class II resinbased composite restorations. J Am Dent Assoc 2007;138: 1487-9.

15. Hahnel S, Schultz S, Trempler C, Ach B, Handel G, Rosentritt M. Two-body wear of dental restorative materials. J Mech Behav Biomed Mater 2011;4:237-44.

16. Mitra SB, Wu D, Holmes BN. An application of nanotechnology in advanced dental materials. J Am Dent Assoc 2003;134: 1382-90.

17. Heintze SD, Cavalleri A, Forjanic M, Zellweger G, Rousson V. Wear of ceramic and antagonist-a systematic evaluation of influencing factors in vitro. Dent Mater 2008;24:433-49.

18. Hmaidouch R, Weigl P. Tooth wear against ceramic crowns in posterior region: a systematic literature review. Int J Oral Sci 2013;5:183-90.

19. Osiewicz MA, Werner A, Pytko-Polonczyk J, Roeters FJ, Kleverlaan CJ. Contact- and contact-free wear between various resin composites. Dent Mater 2015;31:134-40.

20. Koottathape N, Takahashi H, Iwasaki N, Kanehira M, Finger WJ. Quantitative wear and wear damage analysis of composite resins in vitro. J Mech Behav Biomed Mater 2014;29:50816.

21. Cao L, Zhao X, Gong X, Zhao S. An in vitro investigation of wear resistance and hardness of composite resins. Int J Clin Exp Med 2013;6:423-30.

22. Sripetchdanond J, Leevailoj C. Wear of human enamel opposing monolithic zirconia, glass ceramic, and composite resin: an in vitro study. J Prosthet Dent 2014;112:1141-50.

23. DeLong R. Intra-oral restorative materials wear: rethinking the current approaches: how to measure wear. Dent Mater 2006;22:702-11.

24. Condon JR, Ferracane JL. Evaluation of composite wear with a new multi-mode oral wear simulator. Dent Mater 1996;12: 218-26.

25. Kadokawa A, Suzuki S, Tanaka T. Wear evaluation of porcelain opposing gold, composite resin, and enamel. J Prosthet Dent 2006;96:258-65.

26. Harrison A. Wear of combinations of acrylic resin and porcelain, on an abrasion testing machine. J Oral Rehabil 1978;5: 111-5.

27. Zheng J, Zhou ZR, Zhang J, Li H, Yu HY. On the friction and wear behaviour of human tooth enamel and dentin. Wear 2003;255:967-74

28. Ekfeldt A, Oilo G. Occlusal contact wear of prosthodontic materials. An in vivo study. Acta Odontol Scand 1988;46:15969.

29. Mahalick JA, Knap FJ, Weiter EJ. Occlusal wear in prosthodontics. J Am Dent Assoc 1971;82:154-9.

30. Blackham JT, Vandewalle KS, Lien W. Properties of hybrid resin composite systems containing prepolymerized filler particles. Oper Dent 2009;34:697-702.

31. Yesil ZD, Alapati S, Johnston W, Seghi RR. Evaluation of the wear resistance of new nanocomposite resin restorative materials. J Prosthet Dent 2008;99:435-43.

32. Palaniappan S, Bharadwaj D, Mattar DL, Peumans M, Van Meerbeek B, Lambrechts P. Nanofilled and microhybrid composite restorations: Five-year clinical wear performances. Dent Mater 2011;27:692-700.

33. Ghazal M, Kern M. The influence of antagonistic surface roughness on the wear of human enamel and nanofilled composite resin artificial teeth. J Prosthet Dent 2009;101:342-9.

34. Lutz F, Phillips RW, Roulet JF, Setcos JC. In vivo and in vitro wear of potential posterior composites. J Dent Res 1984;63: 914-20.

35. Mair LH, Stolarski TA, Vowles RW, Lloyd CH. Wear: mechanisms, manifestations and measurement. Report of a workshop. J Dent 1996;24:141-8.

36. Braem M, Lambrechts P, Van Doren V, Vanherle G. In vivo evaluation of four posterior composites: quantitative wear measurements and clinical behavior. Dent Mater 1986;2:10613.

37. Preis V, Schmalzbauer M, Bougeard D, Schneider-Feyrer S, Rosentritt M. Surface properties of monolithic zirconia after dental adjustment treatments and in vitro wear simulation. J Dent 2015;43:133-9.

38. Seghi RR, Rosenstiel SF, Bauer P. Abrasion of human enamel by different dental ceramics in vitro. J Dent Res 1991;70:2215 . 